\title{
Geographic Distribution of Households with Goats and Women's Adverse Pregnancy Outcomes and Perceptions of Healthcare Providers Toward Risk of Exposure to Goats or Their Raw Products in Pregnant Women
}

Kan Kledmanee, D.V.M., M.Sc., Tippawan Liabsuetrakul, M.D., Ph.D. Epidemiology Unit, Faculty of Medicine, Prince of Songkla University, Hat Yai, Songkhla 90110, Thailand. Received 9 March 2019 • Revised 30 April 2019 • Accepted 2 May 2019 • Published online 19 June 2019

\section{Abstract:}

Objective: To identify the geographic distribution of households with goats and rates of adverse pregnancy outcomes in women, and assess healthcare providers' perceptions towards risk of adverse pregnancy outcomes related with exposure to goats or their raw products during pregnancy and their intention to do risk screening.

Material and Methods: A cross-sectional study was conducted in Songkhla province using the number of households with goats and the rates of abortion, stillbirth, and preterm birth reported in the Thailand 2015 Universal Coverage Scheme database. The perceptions towards risk of exposure to goats or their raw products and the intention to do risk screening according to the Health Belief Model of 46 healthcare providers from four districts of this province were using correlation analysis and multiple linear regression.

Results: A high number of households with goats was found in all four districts but the number of households with goats was not significantly correlated with any of the rates of adverse pregnancy outcomes. Most perceptions of healthcare providers were highly correlated with intention to do risk screening, except their perceptions on barriers. Cues to action was significantly ( $p$-value=0.018) associated with intention to do risk screening in multiple regression analysis.

Conclusion: No correlation between the number of households with goats and rates of adverse pregnancy outcomes were found; however, healthcare providers had positive perceptions and intention to do risk screening for exposure to goats or their raw products in pregnant women. Education and warning messages concerning zoonosis as strengthening cues to action are needed.

Keywords: adverse pregnancy outcomes, goats, healthcare providers, perceptions, raw goat products, risk screening

Contact: Prof. Tippawan Liabsuetrakul, M.D., Ph.D.

Epidemiology Unit, Faculty of Medicine, Prince of Songkla University,

Hat Yai, Songkhla 90110, Thailand.

E-mail: Itippawa@yahoo.com
J Health Sci Med Res 2019;37(3):217-227 doi: 10.31584/jhsmr.201955 www.jhsmr.org 


\section{Introduction}

Due to increasing market demand, goat businesses have been expanding worldwide, particularly in Asian countries, during recent decades. ${ }^{1}$ Goat production in Thailand has been promoted according to a national policy. As a result, dairy and meat goat populations have grown rapidly in many regions including southern Thailand, where Thai Muslim communities are common. ${ }^{2}$ Intensive production, animal movements, and poor hygiene practices create an increased risk of spreading animal-derived infectious diseases. ${ }^{3}$ In general, these zoonotic diseases can be transmitted from infected goats to humans, leading to human health impairment in endemic areas. ${ }^{4,5}$ Younger, older, or immunocompromised people and pregnant women are at greater risk of contracting zoonotic diseases than healthy individuals. Toxoplasmosis, brucellosis, and coxiellosis are common bacterial zoonotic diseases reported in pregnant women at risk due to a history of raw goat meat or milk consumption or living in areas where those diseases are endemic. ${ }^{5-7}$ Earlier studies have found goats domesticated in Thailand were seropositive for these three pathogens. $^{8-10}$ Previous studies have found that adverse pregnancy outcomes were the major risk to women's health in relation to these zoonotic diseases. ${ }^{11-13}$ In southern Thailand, a previous study found that pregnant women seropositive for brucellosis were more likely to have a history of exposure to raw goat products. ${ }^{14}$ This increased risk requires special attention from public health authorities about the health threat from goat raising and exposure to raw goat products.

In health prevention, healthcare providers are the key personnel in the human health sector in communications with people about ways to promote good health. An improved understanding of healthcare providers' perceptions toward zoonotic diseases is essential for establishing effective practices to improve diagnosis and treatment of these diseases. ${ }^{15}$ The Health Belief Model (HBM) is a framework for addressing individuals' perceptions that evoke health concerns, which leads to their intention to do preventive health care action thereafter. ${ }^{16,17}$ The model comprises six components, perceived susceptibility (perceived vulnerability to an unwanted condition), perceived seriousness (perceived severity of contracting an unwanted condition), perceived benefits (perceived advantages to encouraging preventive behaviors), perceived barriers (perceived limitations of preventive behaviors), self-efficacy (belief in being able to successfully instill the preventive behaviors in the target population), and cues to action (triggers or facilitators for beginning a preventive behaviors program). This HBM model can be used as a tool for evaluating individuals' perceptions regarding preventive action not only at the patient level, but also at the healthcare provider level. ${ }^{18,19}$ The issue of infection from animals to humans, particularly in areas with high goat populations, has been to date neglected in southern Thailand, and there is little or no information concerning the attitudes of local healthcare providers to these risks available. This study aimed to (i) identify the geographic distribution of households with goats and rates of adverse pregnancy outcomes in women, and (ii) assess healthcare providers' perceptions towards risk of adverse pregnancy outcomes related to exposure to goats or their raw products during pregnancy and their intention to do risk screening.

\section{Material and Methods}

\section{Study design and setting}

A cross-sectional study was conducted including a secondary analysis using the database of the Thailand 2015 Universal Coverage Scheme for geographic distribution and a survey of healthcare providers for their perceptions. For the geographic distribution information, all districts of Songkhla province were selected as the study area because Songkhla province is located in southern Thailand, where goat production is popular for household 
consumption and marketing (Figure 1). ${ }^{20}$ The top four districts ranked by numbers of households with goats in the province were Chana, Thepha, Saba Yoi, and $\mathrm{Na}$ Thawi districts, which were then chosen for the study of healthcare providers' perceptions carried out from 1 October to 30 November 2016.

The study was approved by the Research Ethics Committee of the Faculty of Medicine, Prince of Songkla University, Thailand (REC No. 56-266-18-1-3 and REC No. 58-061-15-1). Site permissions were also obtained from the directors of the Provincial and District Public Health Offices for each study setting. Written consent forms were collected from all recruited healthcare providers for their perceptions.

\section{Data for the geographic distribution study}

There are 16 districts, 129 sub-districts, and 497,127 households in Songkhla province, which has a land area of 7,394 square kilometers. ${ }^{21}$ We obtained the number of registered households with goats in each district in 2015 of the province from the Songkhla Provincial Livestock Office (available from: http://pvlo-sgk.dld.go.th). This dataset was employed to create a thematic map which was then used as a base map to access data on adverse pregnancy outcome rates reported in the same year. The data on obstetric health conditions among pregnant women in 2015 of each district of the province was retrieved from the National Health Security Office database, Thailand. Adverse pregnancy outcomes including abortion

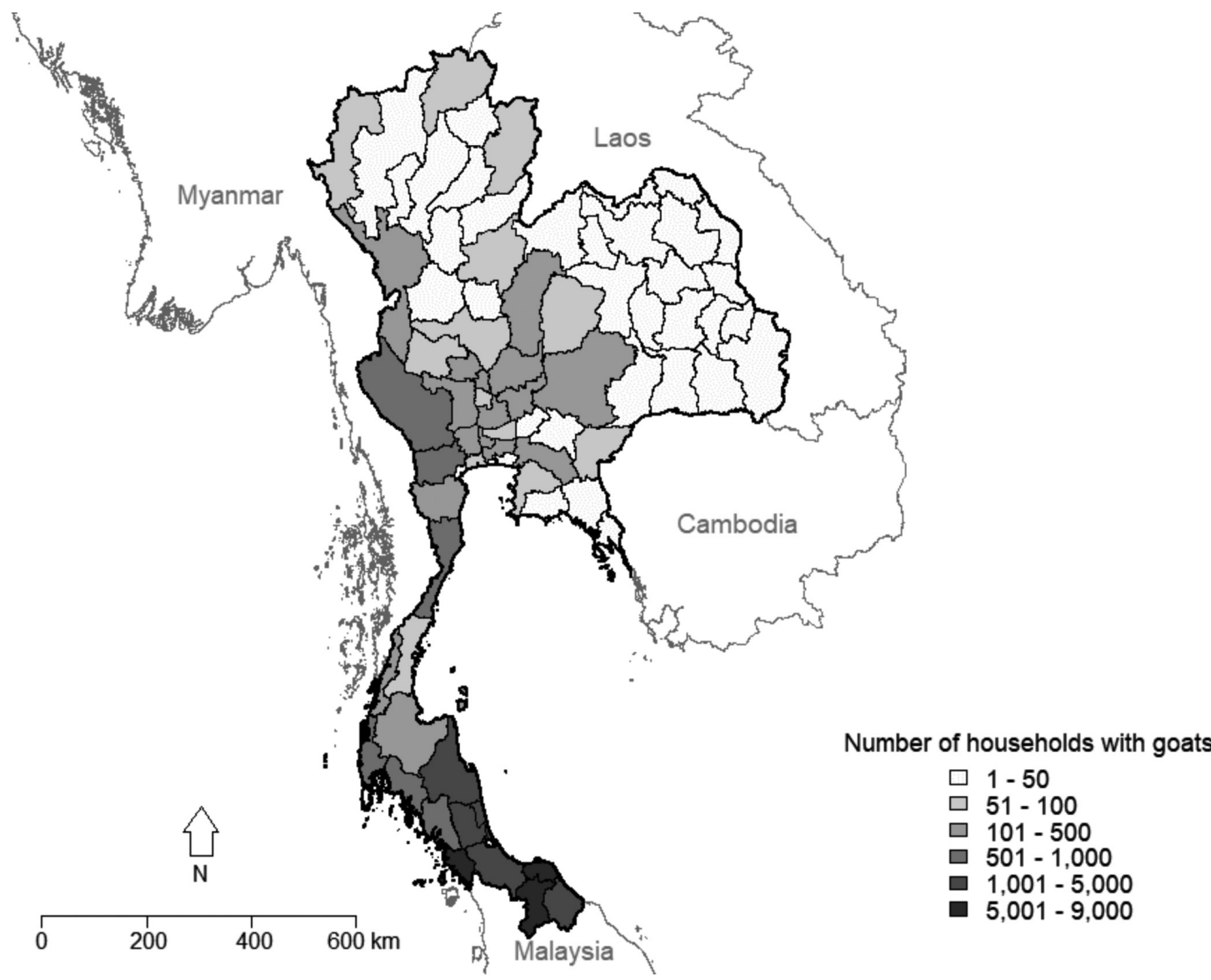

Figure 1 Distribution of households with goats by provinces of Thailand in 2015 
(premature expulsion of an embryo or fetus from the uterus up to 23 weeks of pregnancy and weighing up to 500 grams), stillbirth (birth of a baby showing no signs of life), and preterm birth (birth before 37 complete gestational weeks) data were gathered from this dataset to create a bubble map based on the adverse pregnancy outcome rates for each district in the province.

\section{Study participants and sample size}

All healthcare providers responsible for antenatal care who worked in primary care units or health promoting hospitals in the four study settings were asked to participate in the study. As a result, the sample size calculation was not applicable.

\section{Data for healthcare providers' perceptions study Preparatory phase}

A questionnaire was constructed to measure the perceptions of healthcare providers regarding the risk of adverse pregnancy outcomes related to exposure to goats or raw goat products (meat or milk). The framework and details of the six components of the HBM, namely perceived susceptibility, perceived seriousness, perceived benefits, perceived barriers, self-efficacy, and cues to action, and the link of intention to do risk screening are presented in Figure 2.

Perceived susceptibility and seriousness of risk of exposure to goats or raw goat products in pregnant women and the perceived benefits of risk screening were assessed through six statements each. Perceived barriers to risk screening were measured in three statements, and selfefficacy and cues to action to do risk screening were measured in two statements. Higher scores indicated higher susceptibility, seriousness, benefits, barriers, selfefficacy and cues to action. Intentions to do risk screening and provide counselling were also measured. Each item was evaluated by a 5-point Likert scale with the options of "strongly disagree", "disagree", "uncertain", "agree”, and "strongly agree".

The components of the HBM statements were validated by three experts including an obstetrician from a district hospital, a lecturer from the Faculty of Nursing, and a nurse who was experienced in antenatal care. The statements were assessed in terms of relevance ("not relevant", "somewhat relevant", "quite relevant” or "highly relevant”), conciseness ("not concise" or "concise"), and clarity ("not clear" or "clear"). The comments were considered and a content validity index was calculated and assessed at 0.81 to 1.00 . The internal consistency of each component was also tested among 20 healthcare providers, and good homogeneity of the constructed components was found with Cronbach's alpha scores ranging from 0.81 to 0.98 .

\section{Data collection phase}

A final constructed questionnaire was given to each participant at their hospital. Before participating in the study, all recruited healthcare providers received an information sheet and a consent form to consider. All of them agreed and signed the consent form resulting in 46 healthcare providers included in the study. They were requested to do the questionnaire by themselves, separately from the other participants. The completed questionnaires were kept in sealed envelopes and collected by the researchers within a month after they were distributed.

Apart from the 27 items of the HBM and the intention to do screening questionnaires, baseline characteristics were collected, including the district of the hospital, age, gender, marital status, educational attainment, current job position, hospital level, working experience, and average number of pregnant women seeking care per week in their workplace. 


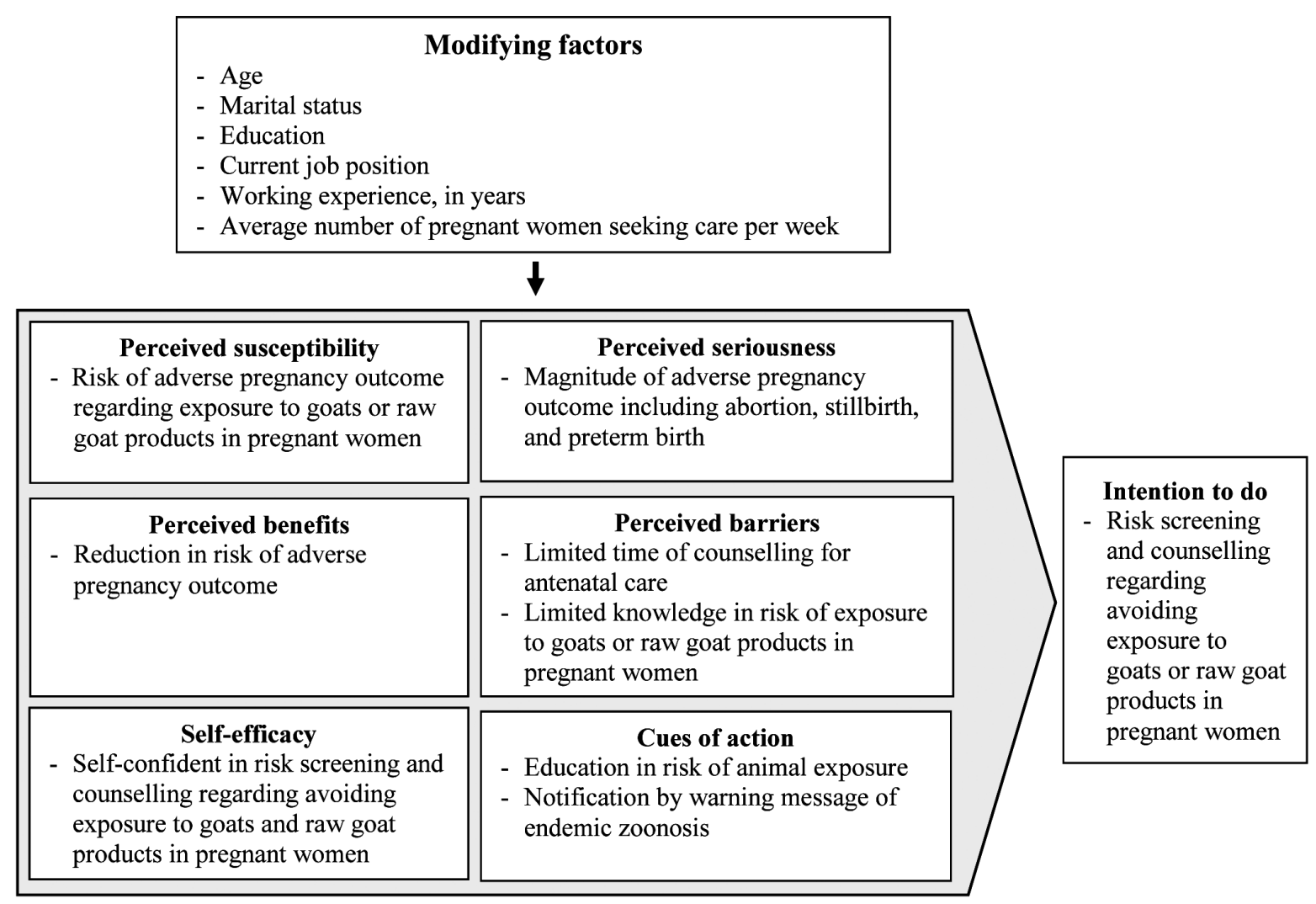

Figure 2 Conceptual framework of the study using a modified Health Belief Model of healthcare providers' perceptions toward risk of adverse pregnancy outcomes related with exposure to goats or raw goat products in pregnant women and their intention to do risk screening

\section{Data analysis}

Data were double-entered into Epi-data version 3.1 and analyzed using $\mathrm{R}$ software. For the geographic distribution study, the data on the number of registered households with goats were analyzed as frequencies and grouped into classes on a thematic map. The rates of adverse pregnancy outcomes including abortions, stillbirths, and preterm births were analyzed in percentages and grouped into classes on a bubble map. Those two data maps were drawn by $\mathrm{R}$ software to determine the geographic distributions of the number of households with goats and the rates of adverse pregnancy outcomes. Pearson's correlation was calculated to analyze the relationship between them.
For the healthcare providers' perceptions study, the baseline characteristics were analyzed in percentages. The scores of the health belief model components were analyzed in means with standard deviations, with the district names anonymized using $A, B, C$, and D instead. One-way analysis of variance (ANOVA) was applied to determine statistically significant differences among the scores of each health belief model component and intention to do risk screening of the healthcare providers from all districts. Where the difference by ANOVA was significant, the post hoc Tukey Honest Significant Difference test was used to detect a difference between the means of all possible pairs. Multiple linear regression analysis was used to predict 
the scores of intention of the scores of the six health belief model components. The level of significance was considered as a $\mathrm{p}$-value less than 0.05 .

\section{Results}

\section{Geographic distribution of number of households} with goats and rates of adverse pregnancy outcomes

The geographic distribution of the number of households with goats and the rates of adverse pregnancy outcomes in the 16 districts of Songkhla are presented in Figure 3. The number of registered households with goats widely varied from 1 to 1,107 households. The top four districts with the highest numbers of registered households with goats were Thepha, Chana, Saba Yoi, and Na Thawi districts $(1,107,967,457$, and 387, respectively). No significant correlations between the number of households with goats and adverse pregnancy outcomes were found. The rates of abortion among these four districts were quite similar (Figure 3a). The rates of stillbirth ranged widely from 0 to 15 per 1,000 deliveries across the province (Figure 3b). The rate of preterm birth was highest in Chana district $(12.4 \%)$, followed by $\mathrm{Na}$ Thawi, Saba Yoi, and Thepha districts $(5.9 \%, 5.6 \%$, and $3.3 \%$, respectively) (Figure 3c).

\section{Characteristics of participants}

A total of 46 healthcare providers from 23 hospitals (1 district hospital, 6 primary care units, and 16 health promoting hospitals) in the 4 study districts were recruited and completed the questionnaire (Table 1). All of them were female and were active in antenatal care screening and counseling for pregnant women. Their mean age was $35.2 \pm 8.1$ years and approximately three-fourths (36/46 $78.3 \%$ ) of them were married or widows. For service a)

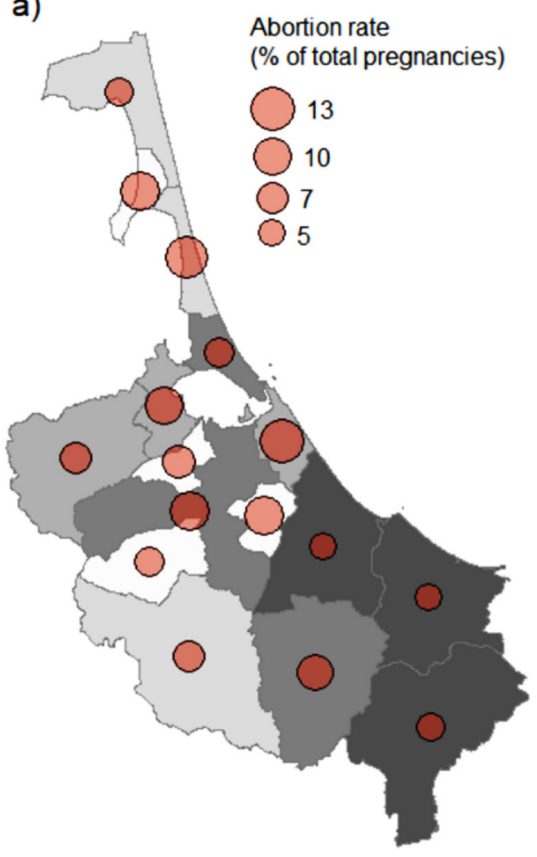

$\square 1-38$ b)

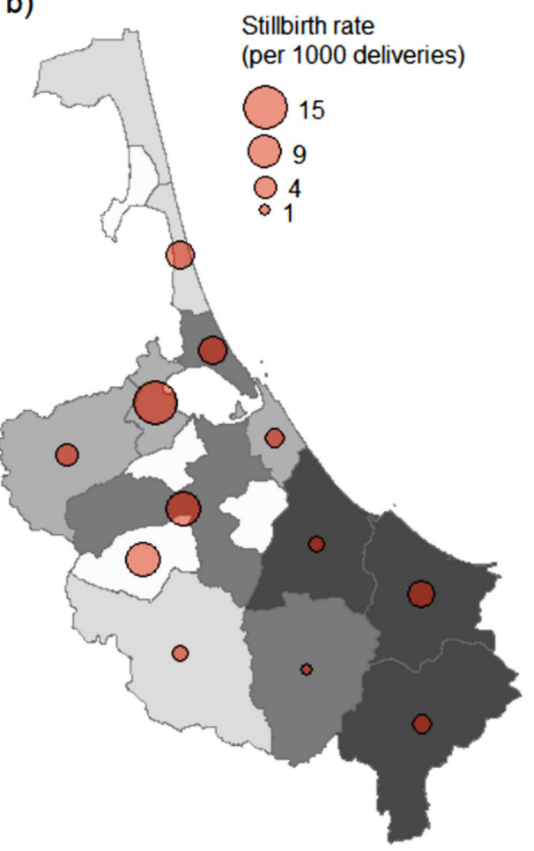

Number of households with goats c)

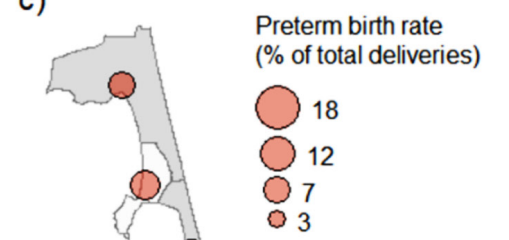

Figure 3 Geographic distribution of households with goats and rates of adverse pregnancy outcomes by districts of Songkhla province in 2015 
information, $10.9 \%$ (5/46) of them had working experience not more than two years. Nearly half of them (22/46 47.8\%) had less than 20 pregnant women seeking care per week.

Table 1 Baseline characteristics of the study healthcare providers $(n=46)$

\begin{tabular}{|c|c|}
\hline Characteristic & $\begin{array}{l}\text { Total } \\
\text { Number (\%) }\end{array}$ \\
\hline \multicolumn{2}{|l|}{ Study setting } \\
\hline \multicolumn{2}{|l|}{ District of hospital } \\
\hline District A & $14(30.4)$ \\
\hline District B & $12(26.1)$ \\
\hline District $C$ & $12(26.1)$ \\
\hline District D & $8(17.4)$ \\
\hline \multicolumn{2}{|l|}{ Personal characteristics } \\
\hline \multicolumn{2}{|l|}{ Age group, in years } \\
\hline $23-34$ & $24(52.2)$ \\
\hline $35-49$ & $19(41.3)$ \\
\hline Over 49 & $3(6.5)$ \\
\hline \multicolumn{2}{|l|}{ Marital status } \\
\hline Single & $10(21.7)$ \\
\hline Married or widow & $36(78.3)$ \\
\hline \multicolumn{2}{|l|}{ Education } \\
\hline Certificate or lower & $4(8.7)$ \\
\hline Bachelor or higher & $42(91.3)$ \\
\hline \multicolumn{2}{|l|}{ Current job position } \\
\hline Nurse & $33(71.7)$ \\
\hline Public health officer & $13(28.3)$ \\
\hline \multicolumn{2}{|l|}{ Service information } \\
\hline \multicolumn{2}{|l|}{ Hospital level } \\
\hline Health promoting hospital & $25(54.3)$ \\
\hline District hospital or primary care unit & $21(46.7)$ \\
\hline \multicolumn{2}{|l|}{ Working experience, in years } \\
\hline $0-2$ & $5(10.9)$ \\
\hline Over 2 & $41(89.1)$ \\
\hline \multicolumn{2}{|c|}{ Average number of pregnant women visits per week } \\
\hline Less than 20 & $22(47.8)$ \\
\hline $20-100$ & $19(41.3)$ \\
\hline Over 100 & $5(10.9)$ \\
\hline
\end{tabular}

$A, B, C$, and D are used for the study districts to maintain anonymity

Perceptions and intention to do risk screening

The healthcare providers' intention to do risk screening and perceptions regarding HBM are shown in
Table 2. Intention to do screening, perceived barriers, self-efficacy and cues to action of the healthcare providers among the four districts were not significantly different. Perceived susceptibility, perceived seriousness and perceived benefits were significantly different across the four districts with the healthcare providers in two districts (districts $B$ and $D$ ) rating these things at high levels compared to the other two districts (districts $\mathrm{A}$ and $\mathrm{C}$ ).

The results of multiple linear regression analysis indicated that at least one of the HBM components was related to their intention to do risk screening (adjusted $R^{2}=$ $0.358, F(6,39)=5.189, p-v a l u e<0.001)$. It was found that cues to action, which were specific education or training and warning message of endemic zoonosis, significantly predicted their intention to do risk screening (coefficient= 0.339, $p$-value $=0.018$ ), while the other factors were not related (Table 3). Most healthcare providers chose print media including brochures or posters as the most effective media to use in counselling pregnant women (mean score $4.5 \pm 0.5$ ), followed by the internet (mean score 4.2 \pm 0.8 ), television (mean score $4.1 \pm 0.7$ ), and radio (mean score $3.9 \pm 0.8)$.

\section{Discussion}

A high variation in the number of households with goats was found in the districts in Songkhla province; however, these variations were not correlated with the rates of women's adverse pregnancy outcomes across the districts in 2015. The intention to do risk screening for exposure to goats and raw goat products in pregnant women was high among healthcare providers in the four districts of the province chosen for the study. The health care providers showed high perceptions of risk exposure and the intention to do risk screening in pregnant women in all components, with cues to action being the most significant component indicating increased intention to do risk screening. 
Table 2 Healthcare providers' scores of intention to do risk screening and their health belief model components for risk of adverse pregnancy outcomes among women exposed to goats or raw goat products during pregnancy $(n=46)$

\begin{tabular}{|c|c|c|c|c|c|}
\hline \multirow[b]{2}{*}{ Component } & \multicolumn{4}{|c|}{ Hospital district } & \multirow{2}{*}{$\begin{array}{l}\text { ANOVA } \\
\text { p-value }\end{array}$} \\
\hline & $\begin{array}{l}\text { A } \\
(n=14)\end{array}$ & $\begin{array}{l}B \\
(n=12)\end{array}$ & $\begin{array}{l}\text { C } \\
(n=12)\end{array}$ & $\begin{array}{l}\text { D } \\
(n=8)\end{array}$ & \\
\hline Intention to do risk screening & & & & & 0.080 \\
\hline Mean (S.D.) & $4.5(0.5)$ & $4.8(0.5)$ & $4.4(0.5)$ & $4.9(0.2)$ & \\
\hline \multicolumn{6}{|l|}{ Health belief model components } \\
\hline Perceived susceptibility & & & & & 0.008 \\
\hline Mean (S.D.) & $3.1(0.8)^{a}$ & $3.9(0.8)^{b}$ & $3.3(0.7)^{\mathrm{ab}}$ & $4.0(0.3)^{b}$ & \\
\hline Perceived seriousness & & & & & 0.014 \\
\hline Mean (S.D.) & $3.0(1.1)^{\mathrm{a}}$ & $3.7(0.7)^{\mathrm{ab}}$ & $3.0(0.9)^{\mathrm{a}}$ & $4.1(0.5)^{b}$ & \\
\hline Perceived benefits & & & & & 0.005 \\
\hline Mean (S.D.) & $3.3(1.0)^{\mathrm{a}}$ & $4.2(0.5)^{b}$ & $3.8(0.3)^{\mathrm{ab}}$ & $4.2(0.5)^{b}$ & \\
\hline Perceived barriers & & & & & 0.500 \\
\hline Mean (S.D.) & $2.9(0.9)$ & $2.6(0.8)$ & $2.8(0.7)$ & $3.2(0.6)$ & \\
\hline Self-efficacy & & & & & 0.345 \\
\hline Mean (S.D.) & $3.4(0.8)$ & $3.9(1.0)$ & $3.3(0.9)$ & $3.3(0.8)$ & \\
\hline Cues to action & & & & & 0.093 \\
\hline Mean (S.D.) & $4.4(0.5)$ & $4.4(0.5)$ & $4(0.4)$ & $4.5(0.5)$ & \\
\hline
\end{tabular}

$A, B, C$, and $D$ is the symbol of study districts to keep it anonymously. ANOVA=analysis of variance, S.D.=standard deviation

$a, b$ Tukey Honest Significant Difference post hoc test: means with the same superscripted letter indicate no significant difference within the same row. Any difference between two means within the same row carrying different superscripted letters is significant at a level of 0.05 .

Table 3 Correlation and regression analyses between all components of the Health Belief Model among healthcare providers with their intention to do risk screening for exposure to goats or raw goat products for pregnant women $(n=46)$

\begin{tabular}{|c|c|c|c|c|c|}
\hline \multirow{2}{*}{ Predictive variable } & \multicolumn{2}{|c|}{ Correlation analysis } & \multicolumn{3}{|c|}{ Multiple regression analysis } \\
\hline & $\mathbf{r}$ & $p$-value & Coefficients & S.E. & $p$-value \\
\hline (Intercept) & - & - & 1.073 & 0.769 & 0.171 \\
\hline Perceived susceptibility & 0.473 & 0.001 & 0.267 & 0.167 & 0.119 \\
\hline Perceived seriousness & 0.438 & 0.002 & -0.037 & 0.139 & 0.794 \\
\hline Perceived benefits & 0.355 & 0.012 & 0.080 & 0.102 & 0.435 \\
\hline Perceived barriers & 0.122 & 0.421 & 0.175 & 0.089 & 0.057 \\
\hline Self-efficacy & 0.389 & 0.008 & 0.138 & 0.083 & 0.105 \\
\hline Cues to action & 0.459 & 0.001 & 0.339 & 0.136 & 0.018 \\
\hline
\end{tabular}

$r=$ correlation coefficient, S.E.=standard error 
We could not find another study examining or comparing the correlation between the numbers of households with goats and rates of women's adverse pregnancy outcomes as our study did. This may be because the causes of adverse pregnancy outcomes are multifactorial including various mechanisms apart from zoonotic diseases in women such as toxoplasmosis, brucellosis and $Q$ fever. ${ }^{22-24}$ Previous studies have reported that pregnant women living in the vicinity of goat farms were at the same risk as the goat farmers of contracting zoonotic infections from a contaminated environment, particularly those living in endemic areas of those diseases. ${ }^{6,25}$

The high level of healthcare providers' intention to do risk screening for exposure to goats or raw goat products during pregnancy in our study indicated that the healthcare providers considered themselves to have a formal role in health promotion and prevention and agreed that recognizing, diagnosing and treating zoonotic diseases among people at risk was an important part of their work. ${ }^{26}$ A previous study conducted in the United States of America showed that the healthcare providers rarely asked about a history of animal exposure when they met their patients. ${ }^{15}$ This reflects the limitations around risk recognition and health education on zoonotic infections.

High perceptions of healthcare providers toward risk of exposure to goats or their raw products in pregnant women were found in our study. This indicates that the healthcare providers perceived the vulnerability and threat of such exposure in pregnant women, as well as the advantages of doing risk screening, a finding in accordance with two previous studies which reported that most healthcare providers perceived the risk of disease transmission in their communities. ${ }^{27,28}$ However, the perception levels differed according to the age and work experience of the healthcare providers. ${ }^{24,25}$ Raw milk was considered to be more risky for pregnant women than raw meat by the healthcare providers in our study, a finding which was similar to a previous study which assumed a lack of healthcare providers' knowledge of the risk factors of disease transmission and barriers to counseling pregnant women. ${ }^{29}$ Cues to action for risk screening, particularly education concerning risk exposure and notification of warning messages, was the most common reason given for an intention to do risk screening among the healthcare providers. Although previous studies did not measure the perceptions using the health belief model as in our study, they also found that when interviewing clients with animal contact, the healthcare providers would request information concerning zoonotic transmission and prevention methods. ${ }^{26,30-32}$ The importance of cues to action recognized among healthcare providers was supported by previous studies which reported that healthcare providers felt a limitation of disease identification and diagnosis in rural areas with prevalent human-livestock interaction and less confidence to give health advice..$^{15,33,34}$

This study was the first, to our knowledge, to examine a potential linkage between animals and human health using the magnitude of households with goats related to women's adverse pregnancy outcomes. Healthcare providers are the key personnel to strengthen health promotion and prevention for zoonotic diseases.

There were some limitations in this study. First, only healthcare providers in four provincial districts were included, and expanding this kind of study to include healthcare providers in other districts is required before the results would be generalizable. Second, data collection based on self-administered questionnaires may have led to some information bias; however, the objectives of the study and the requirements of actual perception and need of risk screening by healthcare providers were explained to all clearly thus this potential bias should have been small. Lastly, although healthcare providers in the 
same hospitals were requested to complete the questionnaires separately, the researcher could not observe them to ensure this requirement was followed.

\section{Conclusion}

A correlation between the number of households with goats and the rates of adverse pregnancy outcomes was not found. Healthcare providers in districts with high numbers of households with goats had positive perceptions and intention to do risk screening for exposure to goats or raw goat products in pregnant women. Cues to action including specific education and warning message of endemic zoonosis was the factor most influencing the intention to do risk screening.

\section{Acknowledgement}

This study was part of the first author's thesis in partial fulfilment of the requirements for a Ph.D. in Epidemiology at Prince of Songkla University, Thailand. The authors would like to thank the Songkhla Provincial Public Health Office and the District Public Health Offices of Chana, Thepha, Saba Yoi, and Na Thawi districts for providing assistance with our contacts with healthcare providers in the four study districts. We are grateful to the National Health Security Office, Thailand for providing and approving the use of their data.

This research was supported by the Thailand Research Fund through the Royal Golden Jubilee PhD Program (Grant No. PHD/0098/2557, to Kan Kledmanee and Tippawan Liabsuetrakul), the National Science and Technology Development Agency of Thailand, the Graduate School Dissertation Funding and the Excellence Center of the Epidemiology Unit Scholarship, Prince of Songkla University.

\section{Conflict of interest}

The authors have no conflict of interest to declare.

\section{References}

1. Food and Agriculture Organization of the United Nations (FAO). Production of goats [homepage on the Internet]. Rome: FAO; 2018 [cited 2018 Jun 30]. Available from: http://www.fao. org/faostat/en/\#data/QA/visualize/

2. Semae S. The success way of goat raising by Muslim way. J Yala Rajabhat Univ 2007;2:72-81.

3. Kimman T, Hoek M, de Jong MCM. Assessing and controlling health risks from animal husbandry. NJAS - Wagening $\mathrm{J}$ Life Sci 2013;66:7-14.

4. Facciolà A, Palamara MAR, D’Andrea G, Marano F, Magliarditi $D$, Puglisi G, et al. Brucellosis is a public health problem in southern Italy: burden and epidemiological trend of human and animal disease. J Infect Public Health 2018;11:861-6.

5. Rossetti CA, Arenas-Gamboa AM, Maurizio E. Caprine brucellosis: a historically neglected disease with significant impact on public health. PLoS Negl Trop Dis 2017;11. doi: 10. 1371/journal.pntd.0005692.

6. van der Hoek W, Meekelenkamp JCE, Dijkstra F, Notermans DW, Bom B, Vellema P, et al. Proximity to goat farms and Coxiella burnetii seroprevalence among pregnant women. Emerg Infect Dis 2011;17:2360-3.

7. Committee on Infectious Diseases; Committee on Nutrition; American Academy of Pediatrics. Consumption of raw or unpasteurized milk and milk products by pregnant women and children. Pediatrics 2014;133:175-9.

8. Jittapalapong S, Sangvaranond A, Pinyopanuwat N, Chimnoi W, Khachaeram W, Koizumi S, et al. Seroprevalence of Toxoplasma gondii infection in domestic goats in Satun Province, Thailand. Vet Parasitol 2005;127:17-22.

9. Doung-ngern P, Chuxnum T, Pangjai D, Opaschaitat P, Kittiwan $N$, Rodtian $\mathrm{P}$, et al. Seroprevalence of Coxiella burnetii antibodies among ruminants and occupationally exposed people in Thailand, 2012-2013. Am J Trop Med Hyg 2017;96: 786-90.

10. Ninprom T, Nonthasorn P, Thiptara A, Kongkaew W. Prevalence and spatial distribution of brucellosis in goats in the southernmost provinces of Thailand in 2014. Thai - NIAH EJournal 2016;11:16-26.

11. Pandey D. Pregnancy outcome in maternal toxoplasmosis: a case control study. Open Access J Gynecol 2018;3:1-6.

12. Ali S, Akhter $S$, Neubauer $H$, Scherag A, Kesselmeier M, 
Melzer F, et al. Brucellosis in pregnant women from Pakistan: an observational study. BMC Infect Dis 2016;16: 468.

13. Jover-Díaz F, Robert-Gates J, Andreu-Gimenez L, MerinoSanchez J. Q fever during pregnancy: an emerging cause of prematurity and abortion. Infect Dis Obstet Gynecol 2001;9: 47-9.

14. Kledmanee K, Liabsuetrakul T, Sretrirutchai S. Risk of adverse pregnancy outcomes and seroprevalence for brucellosis in pregnant women exposed to goats or raw goat products in southern Thailand: a prospective cohort study. BMC Pregnancy Childbirth 2019;19:118.

15. Kersting AL, Medeiros LC, LeJeune JT. Zoonoses and the physicians' role in educating farming patients. J Agromedicine 2009;14:306-11.

16. Janz NK, Becker MH. The health belief model: a decade later. Health Educ Behav 1984;11:1-47.

17. Yarbrough SS, Braden CJ. Utility of health belief model as a guide for explaining or predicting breast cancer screening behaviours. J Adv Nurs 2001;33:677-88.

18. Bednarczyk RA, Chamberlain A, Mathewson K, Salmon DA, Omer SB. Practice-, provider-, and patient-level interventions to improve preventive care: development of the P3 Model. Prev Med Rep 2018;11:131-8.

19. Wong S, Marcus R, Hawkins M, Shallow S, McCombs KG, Swanson E, et al. Physicians as food-safety educators: a practices and perceptions survey. Clin Infect Dis 2004;38: S212-8.

20. Department of Livestock. Farmers and livestock in 2015 [homepage on the Internet]. Bangkok: Department of Livestock; 2015 [cited 2015 Jan 23]. Available from: https://data.go.th/

21. Songkhla Provincial Statistics Office. Provincial Statistica Report 2015 [homepage on the Internet]. Songkhla: Songkhla Provincial Statistics Office; 2015 [cited 2018 Jan 23]. Available from: http://songkhla.nso.go.th/

22. Nielsen SY, Mølbak K, Henriksen TB, Krogfelt KA, Larsen CS, Villumsen S. Adverse pregnancy outcomes and Coxiella burnetii antibodies in pregnant women, Denmark. Emerg Infect Dis 2014;20:925-31.

23. Akbarian Z, Ziay G, Schauwers W, Noormal B, Saeed I, Qanee $\mathrm{AH}$, et al. Brucellosis and Coxiella burnetii infection in householders and their animals in secure villages in Herat province,
Afghanistan: a cross-sectional study. PLoS Negl Trop Dis 2015;9:1-17.

24. Kramer MS, Zhang X, Platt RW. Analyzing risks of adverse pregnancy outcomes. Am J Epidemiol 2014;179:361-7.

25. Te-Chaniyom T, Geater AF, Kongkaew W, Chethanond U, Chongsuvivatwong V. Goat farm management and Brucella serological test among goat keepers and livestock officers, 2011-2012, Nakhon Si Thammarat province, southern Thailand. One Health 2016;2:126-30.

26. Speare R, Mendez D, Judd J, Reid S, Tzipori S, Massey PD. Willingness to consult a veterinarian on physician's advice for zoonotic diseases: a formal role for veterinarians in medicine? PLoS One 2015;10. doi: 10.1371/journal.pone. 0131406.

27. Dunn BS, Tice AD, Dc ELH, Katz AR. Knowledge and perceptions about community-acquired Staphylococcal infections among health care workers in Hawai'i. Hawaii $\mathrm{J}$ Med Public Health 2013;72:6.

28. Weng YH, Bhembe PT, Chiou HY, Yang CY, Chiu YW. Perceived risk of tuberculosis infection among healthcare workers in Swaziland. BMC Infect Dis 2016;16:1-8.

29. Kirkham C, Berkowitz J. Listeriosis in pregnancy: survey of British Columbia practitioners' knowledge of risk factors, counseling practices, and learning needs. Can Fam Physician 2010;56:158-66.

30. Zhang HL, Mnzava KW, Mitchell ST, Melubo ML, Kibona TJ, Cleaveland S, et al. Mixed methods survey of zoonotic disease awareness and practice among animal and human healthcare providers in Moshi, Tanzania. PLoS Negl Trop Dis 2016;10. doi: 10.1371/journal.pntd.0004476.

31. Weng HY, Ankrom K. Practices and perceptions of animal contact and associated health outcomes in pregnant women and new mothers. Front Vet Sci 2016;3:1-7.

32. Hill WA, Petty GC, Erwin PC, Souza MJ. A survey of Tennessee veterinarian and physician attitudes, knowledge, and practices regarding zoonoses prevention among animal owners with HIV infection or AIDS. J Am Vet Med Assoc 2012;240:1432-40.

33. Grant S, Olsen CW. Preventing zoonotic diseases in immunocompromised persons: the role of physicians and veterinarians. Emerg Infect Dis 1999;5:159.

34. John K, Kazwala R, Mfinanga GS. Knowledge of causes, clinical features and diagnosis of common zoonoses among medical practitioners in Tanzania. BMC Infect Dis 2008;8:162. 